\title{
Influence of Meta-Topolin on Efficient Plant Regeneration via Micropropagation and Organogenesis of Safflower (Carthamus tinctorius L.) cv. NARI-H-15
}

\author{
Jeyachandran Vijayakumar1*, Ponnirul Ponmanickam², P. Samuel1, D. N. P. Sudarmani², \\ J. Pandiarajan' 1
}

${ }^{1}$ Department of Biotechnology, Ayya Nadar Janaki Ammal College, Sivakasi, India

${ }^{2}$ Department of Zoology, Ayya Nadar Janaki Ammal College, Sivakasi, India

Email: *georgejarsvijay2004@yahoo.com, *drjvijayakumar15@gmail.com

How to cite this paper: Vijayakumar, J., Ponmanickam, P., Samuel, P., Sudarmani, D.N.P. and Pandiarajan, J. (2017) Influence of Meta-Topolin on Efficient Plant Regeneration via Micropropagation and Organogenesis of Safflower (Carthamus tinctorius L.) cv. NARI-H-15. American Journal of Plant Sciences, 8, 688-705.

https://doi.org/10.4236/ajps.2017.84048

Received: January 26, 2017

Accepted: March 13, 2017

Published: March 16, 2017

Copyright $\odot 2017$ by authors and Scientific Research Publishing Inc. This work is licensed under the Creative Commons Attribution International License (CC BY 4.0).

http://creativecommons.org/licenses/by/4.0/

c. (i) Open Access

\begin{abstract}
The effect of meta-Topolin (mT) was assessed to develop a reliable protocol for efficient plant regeneration of safflower (Carthamus tinctorius L.) cv. NARI-H-15. For micropropagation, 7 - 9 days old shoot-tip explants cultured on MS basal medium supplemented with $3.0 \mathrm{mg} / \mathrm{L}$ meta-Topolin $(\mathrm{mT})+0.5$ $\mathrm{mg} / \mathrm{L}$ CPPU showed $97.7 \%$ adventitious shoot formation (42.4 shootlets) than node after 45 days of culture. For organogenesis, the seedling explants of immature leaf cultured on $1.5 \mathrm{mg} / \mathrm{L}$ CPPU or $1.5 \mathrm{mg} / \mathrm{L}$ NAA fortified medium produced high amount of callus than cotyledon and stem calli after 60 days of culture. However, MS basal medium fortified with $4.0 \mathrm{mg} / \mathrm{L} \mathrm{mT}+1.5 \mathrm{mg} / \mathrm{L}$ CPPU was found beneficial to stimulate $100 \%$ organogenic response $(74.7$ shootlets) from immature leaf calli than cotyledon and stem derived calli after 45 days of culture. The healthy plantlets obtained from micropropagation and organogenesis process cultured on $1 / 4$ MS basal salts, $1.5 \%$ sucrose $(\mathrm{w} / \mathrm{v})$ and $0.8 \%$ agar $(\mathrm{w} / \mathrm{v})$ medium supplemented with NAA $(1.5 \mathrm{mg} / \mathrm{L})$ and $\mathrm{mT}(0.1$ $\mathrm{mg} / \mathrm{L}$ ) produced maximum of $96 \%$ (12.8 rootlets) and $84 \%$ (7.3 rootlets) adventitious rooting, respectively than $\mathrm{mT}$ and CPPU tested medium. However, maximum of $67 \%$ and $42 \%$ survival rate was noticed when in vitro raised plants from micropropagation and organogenesis were hardened in pots containing soil mix and maintained under green house condition. This optimized regeneration protocol might be helpful in regeneration of new genotypes and cultivars of safflower to improve agronomic traits through in vitro selection process and Agrobacterium-mediated genetic transformation system.
\end{abstract}

\section{Keywords}

Carthamus Tinctorius L., Meta-Topolin, N-(2-chloro-4-pyridyl-N'-phenylurea), 
Micropropagation, Organogenesis

\section{Introduction}

Safflower (Carthamus tinctorius L.) belongs to the family Asteraceae, is a very important oil plant native to India, but is widely distributed in most warm countries. Seeds are used for the extraction of edible oil, flowers utilized for colouring foods and leaves are used as salad vegetable. In India, Pakistan and neighboring countries, a seed rate of $5-12 \mathrm{Kg} / \mathrm{ha}$ is common, the average seed yield of commercially grown safflower has increased steadily to around 1500 $\mathrm{Kg} / \mathrm{ha}$, nearly twice under irrigation [1]. The leaves and shoots of safflower are used as pot herb and salad. The mass of young plants are commonly sold as a green vegetable in markets in India and some neighboring countries [2]. Safflower and Sunflower seed oil have a significant amount of essential fatty acids Omega-3 and Omega 6. Safflower has attracted very little attention as far as tissue culture and genetic transformation are concerned. Initial efforts in safflower were directed to develop suitable culture conditions for whole plant regeneration. It has been demonstrated that regeneration frequencies are very high, and regeneration is possible through organogenesis and embryogenesis pathways. In earlier, the plant regeneration from different explants of safflower cultivars was studied by some researchers and very limited literature is available [3]-[18]. The choice of cytokinin to be used in a tissue culture is determined by its cumulative efficiency in inducing an acceptable rate of shoot multiplication which depends on safflower cultivars. BAP or TDZ along with auxins are reported to cause hyperhydricity with minimum rate of shoot multiplication in many cultivars of safflower plants. Therefore it is very important to find an alternative cytokinin to maintain a reasonable shoot development rate and sufficient plant quality under in vitro condition.

Recently, the use of meta-Topolins (mT) indicates a new source of cytokinins that could be suited to promote high morphogenetic development. $\mathrm{mT}$ is a highly active aromatic cytokinin from poplar leaves (Populus $\times$ canadensis Moench) [19]. The $\mathrm{mT}$ group compound can be considered as an alternative to other commonly used cytokinins in regeneration of recalcitrant plant species. In earlier studies, $\mathrm{mT}$ group cytokinin and its derivatives have a comparable effect on in vitro regeneration of sugar beet [20], Curcuma longa [21], Aloe polyphylla [22], banana cv. Williams [23]. Researchers found that $\mathrm{mT}$ was nearly twice as effective as BA in the induction of shoot growth. The structural difference with $\mathrm{mT}$ and synthetic phenylurea derivatives of $N$-(2-chloro-4-pyridyl)- $N$-phenylurea (CPPU) could have a profound impact on plant regeneration during micropropagation and organogenesis. Thus, there are still no data concerning in vitro regeneration using $\mathrm{mT}$ as cytokinin for different safflower genotypes. Therefore, the study aimed to develop a reliable and efficient in vitro regeneration system of safflower cv. NARI-H-15 through micropropagation and organogenesis for 
commercial propagation suitable for improving agronomic traits.

\section{Material and Methods}

\subsection{Plant Material}

Safflower (C. tinctorius L.) seeds of cv. NARI-H-15 were obtained from the Nimbhkar Agricultural Research Institute (NARI), Maharashtra, India for the present study. It is a spiny variety selected based on their area of cultivation in agro-climatic conditions.

\subsection{In Vitro Seed Germination and Culture Condition}

Safflower seeds (cv. NARI-H-15) were soaked with $1.0 \%$ Teepol (commercial bleach solution, $0.6 \%$ sodium hypochlorite, Rockitt Benckiser (India) Ltd., Kolkata, India) solution for $30 \mathrm{sec}$ and kept under tap water for 20 min to remove detergent. Further processes were carried out under aseptic conditions by treating with $70 \%$ ethanol (v/v) for $1 \mathrm{~min}$ and rinsed twice with sterile distilled water for 2 min followed by $0.1 \% \mathrm{HgCl}_{2}$ (mercuric chloride) for $2 \mathrm{~min}$. The surface sterilized seeds were implanted in MS medium [24] containing 3.0\% sucrose $(\mathrm{w} / \mathrm{v})$ and $0.8 \%$ agar (w/v) (Hi-media laboratories limited, Mumbai, India). All the cultures were initially incubated in darkness for $24 \mathrm{hr}$ and later transferred to $16 / 8$-hr light/dark conditions at $25^{\circ} \mathrm{C}$ under $15 \mu \mathrm{mol} \mathrm{m}{ }^{-2} \cdot \mathrm{s}^{-1}$ provided by cool white fluorescent tubes (Philips, India) for in vitro seed germination.

\subsection{Microshoot Initiation and Proliferation}

Approximately 0.5 to $1.5 \mathrm{~cm}$ long shoot-tip and node (7 - 9 days old) explants were trimmed by surgical blade and inoculated on MS medium supplemented with macro and micronutrients, $3.0 \%$ sucrose and $0.8 \%$ agar with various concentrations of an individual cytokinins, BAP or $\mathrm{mT}$ or TDZ or Kin or Zeatin or CPPU or 2-iP or Diuron or Monuron ranged from $1.0-9.0 \mathrm{mg} / \mathrm{L}$ alone or optimum level of BAP $(7.0 \mathrm{mg} / \mathrm{L})$ or $\mathrm{mT}(3.0 \mathrm{mg} / \mathrm{L})$ or TDZ $(5.0 \mathrm{mg} / \mathrm{L})$ in combination with different concentration of CPPU $(0.1-2.5 \mathrm{mg} / \mathrm{L})$. All cultures were incubated at $25^{\circ} \mathrm{C} \pm 2{ }^{\circ} \mathrm{C}$ under continuous irridation with white fluorescent tube $\left(15 \mu \mathrm{mol} \mathrm{m}{ }^{-2} \cdot \mathrm{s}^{-1}\right)$ for $16 \mathrm{hr}$ photoperiod for microshoot initiation and proliferation. Each experiment was repeated thrice. Every subculture was done after 2 weeks of interval. Data were collected on the frequency of plant regeneration, mean number of shoot formation and elongation of shoots in the same culture condition after 45 days of culture.

\subsection{Indirect Organogenesis}

\subsubsection{Callogenesis}

The primary explants of cotyledon, immature leaf and stem were excised from 7 - 9 days old in vitro seedlings. All explants were dissected into $0.5-1.0 \mathrm{~cm}$ length and wounded by using a sterile surgical blade. Cotyledon and immature leaf lobe explants were placed with the right side up (abaxial surface into the medium) or upside down (adaxial surface into the medium), and node segments 
were placed horizontally into culture tubes $(25 \times 150 \mathrm{~mm})$ each containing 15 $\mathrm{ml}$ MS basal salts, $3.0 \%(\mathrm{w} / \mathrm{v})$ sucrose medium supplemented with with different ranges $(0.5-2.5 \mathrm{mg} / \mathrm{L})$ of individual auxins, NAA, IBA, IAA, 2,4-D, Dicamba, CPPU, pCPA and Picloram. The initiation of calli from wounded cotyledon, immature leaf and stem explants were subcultured at two weeks intervals. There were 35 explants/treatment and the experiment was repeated three times. Callusing efficiency was defined as the percentage of explants that produced callus per culture tube. The average fresh weight and dry weight of the callus was determined at each treatment after 60 days of culture.

\subsubsection{Organogenesis}

After calli initiation, approximately $200 \mathrm{mg}$ of calli were isolated from both immature leaf and stem explants and subcultured on MS basal salts with $3.0 \%(\mathrm{w} / \mathrm{v})$ sucrose medium supplemented with different concentrations of an individual cytokinins, BAP $(3.0$ - 9.0 mg/L) or $\mathrm{mT}(1-5 \mathrm{mg} / \mathrm{L})$ or TDZ $(3.0-9.0 \mathrm{mg} / \mathrm{L})$ or CPPU $(1-5 \mathrm{mg} / \mathrm{L})$ or BAP $(7.0 \mathrm{mg} / \mathrm{L})+\mathrm{Kin}(0.5-2.0 \mathrm{mg} / \mathrm{L})$ or BAP $(7.0 \mathrm{mg} / \mathrm{L})$ + CPPU (0.5 - $2.0 \mathrm{mg} / \mathrm{L})$ or BAP $(7.0 \mathrm{mg} / \mathrm{L})+\mathrm{NAA}(0.5-2.0 \mathrm{mg} / \mathrm{L})$ or BAP $(7.0$ $\mathrm{mg} / \mathrm{L})+\mathrm{IAA}(0.5-2.0 \mathrm{mg} / \mathrm{L})$ or BAP $(7.0 \mathrm{mg} / \mathrm{L})+\mathrm{IBA}(0.5-2.0 \mathrm{mg} / \mathrm{L})$ or $\mathrm{mT}$ $(4.0 \mathrm{mg} / \mathrm{L})+\operatorname{Kin}(0.5-2.0 \mathrm{mg} / \mathrm{L})$ or $\mathrm{mT}(4.0 \mathrm{mg} / \mathrm{L})+\mathrm{CPPU}(0.5-2.0 \mathrm{mg} / \mathrm{L})$ or $\mathrm{mT}(4.0 \mathrm{mg} / \mathrm{L})+\mathrm{NAA}(0.5-2.0 \mathrm{mg} / \mathrm{L})$ or $\mathrm{mT}(4.0 \mathrm{mg} / \mathrm{L})+\mathrm{IAA}(0.5-2.0 \mathrm{mg} / \mathrm{L})$ or $\mathrm{mT}(4.0 \mathrm{mg} / \mathrm{L})+\mathrm{IBA}(0.5-2.0 \mathrm{mg} / \mathrm{L})$ or $\mathrm{TDZ}(5.0 \mathrm{mg} / \mathrm{L})+\mathrm{Kin}(0.5-2.0$ $\mathrm{mg} / \mathrm{L})$ or TDZ $(5.0 \mathrm{mg} / \mathrm{L})+\mathrm{CPPU}(0.5-2.0 \mathrm{mg} / \mathrm{L})$ or TDZ $(5.0 \mathrm{mg} / \mathrm{L})+\mathrm{NAA}$ $(0.5-2.0 \mathrm{mg} / \mathrm{L})$ or TDZ $(5.0 \mathrm{mg} / \mathrm{L})+\mathrm{IAA}(0.5-2.0 \mathrm{mg} / \mathrm{L})$ or TDZ $(5.0 \mathrm{mg} / \mathrm{L})+$ IBA $(0.5-2.0 \mathrm{mg} / \mathrm{L})$ for organogenic calli formation and adventitious microshoot induction. There were 40 explants/treatment and the experiments were carried out three times. Data on percent of shoot organogenesis (percentage of explants producing shoot buds) and number of microshoot buds were recorded after 45 days of culture.

\subsection{Rooting and Hardening of Plants}

The individual plantlets were isolated from the clumps of shoots on shoot-tip, node explants culture (micropropagation) and also from cotyledon, immature leaf and stem derived calli (organogenesis) and trimmed to above $0.5-2.0 \mathrm{~cm}$ length and placed on quarter strength MS salts with $1.5 \%$ sucrose medium supplemented with different levels of an individual auxins, NAA or IAA or IBA (0.5 - $2.5 \mathrm{mg} / \mathrm{L})$ alone or NAA $(2.0 \mathrm{mg} / \mathrm{L})+\mathrm{BAP}(0.1-0.5 \mathrm{mg} / \mathrm{L})$ or NAA $(1.5 \mathrm{mg} / \mathrm{L})$ + CPPU (0.1 - $0.5 \mathrm{mg} / \mathrm{L})$ or NAA $(1.5 \mathrm{mg} / \mathrm{L})+\mathrm{mT}(0.1-0.5 \mathrm{mg} / \mathrm{L})+\mathrm{NAA}(1.5$ $\mathrm{mg} / \mathrm{L})+\mathrm{AgNO}_{3}(0.1-0.5 \mathrm{mg} / \mathrm{L})$ for the frequency of root induction. There were 35 plantlets/treatment and the experiments were carried out three times. Data were recorded on per cent of root induction after 30 days of culture. For first stage of hardening, plantlets with well developed roots were carefully removed from the culture tubes and washed under running tap water to remove agar gels from the roots and were transplanted onto $6.0 \mathrm{~cm}$ diameter plastic cups containing the mixture of sterile red soil, garden soil and sand in the ratio of 1:2:1. To maintain high humidity the plastic cups were covered with polythene bags. A 
narrow cut $(2.0 \mathrm{~cm})$ was made in each bag after $24 \mathrm{~h}$. Plantlets were irrigated with $5 \mathrm{ml}$ of half-strength MS inorganic salts and subsequently with distilled water during the first two weeks. The polythene bags were then removed and plants were acclimatized in earthen pots containing soil mixture with vermiculite in the second stage of hardening. All acclimatized plants were maintained under $15 \mu \mathrm{mol} \mathrm{m}{ }^{-2} \cdot \mathrm{s}^{-1}$ in $16-\mathrm{hr}$ photoperiod provided by cool white fluorescent tubes at $25^{\circ} \mathrm{C} \pm 2^{\circ} \mathrm{C}$ for another 2 weeks before the plants were transferred to the greenhouse.

\subsection{Data Analysis}

The direct shoot induction from meristem explants via micropropagation and shoot organogenesis from callus culture was determined. Regeneration frequency was evaluated based on plantlet and rootlet production per explants. Each experiment was conducted in three replicates in completely randomized block design. Data presented are means \pm standard error for independent experiments. Data were analyzed using analysis of variance (ANOVA) and differences of means were evaluated by Duncan's multiple range test (DMRT) of SPSS statistical package version 12. This software was used for expressing the statistical significance obtained by comparing plant regeneration through micropropagation and organogenesis.

\section{Results}

\subsection{Micropropagation Response}

In order to have successful in vitro regeneration, factors such as explant type and culture conditions are very important. In this study, microshoot buds were initiated from 7 - 9 days old shoot-tip and node explants and grew into tiny visible shoots in cytokinin supplemented media (Figure 1(a)) In this case, MS basal salts, 3.0\% sucrose $(\mathrm{w} / \mathrm{v}), 0.8 \%$ agar $(\mathrm{w} / \mathrm{v})$ medium supplemented with BAP (7.0 $\mathrm{mg} / \mathrm{L}$ ) influenced $77.4 \%$ and $72.9 \%$ shoot regeneration with an average of 16.5 and 12 number of shootlet formation from shoot-tip and node explants, respectively after 45 days of culture. $\mathrm{mT}$ at $3.5 \mathrm{mg} / \mathrm{L}$ induced $88.6 \%$ and $80 \%$ shoot regeneration with an average of 21 and 19 shootlets per shoot-tip and node explants, respectively. TDZ at $5.0 \mathrm{mg} / \mathrm{L}$ influenced $80.6 \%$ and $73.7 \%$ shoot regeneration with an average of 18 and 17.2 number of microshoots per shoot-tip and node explants culture, respectively. CPPU at $3.0 \mathrm{mg} / \mathrm{L}$ induced $58 \%$ and $54.9 \%$ shoot regeneration with an average of 12 and 10 number of shootlets per shoottip and node explants, respectively. Diuron and Monuron supplemented medium showed moderate response to induce adventitious shoot formation in both shoot-tip and node explants than Kin, Zeatin and 2-iP tested medium. About $85.7 \%$ and $78.3 \%$ shoot induction frequency with an average of 33.5 and 31 number of shootlets was noticed from shoot-tip and node explants cultured on MS medium fortified with BAP $(7.0 \mathrm{mg} / \mathrm{L})+\mathrm{CPPU}(1.5 \mathrm{mg} / \mathrm{L}) . \mathrm{TDZ}(5.0 \mathrm{mg} / \mathrm{L})$ + CPPU $(0.5 \mathrm{mg} / \mathrm{L})$ induced $90.9 \%$ and $84.3 \%$ shoot regeneration frequency with an average of 39 and 35 number of shootlets in shoot-tip and node explants cul- 
ture, respectively. However, about $97.7 \%$ shoot induction frequency with an average of 42.4 number of shootlets was noticed in shoot-tip than node explants cultured on MS medium fortified with $\mathrm{mT}(3.0 \mathrm{mg} / \mathrm{L})+\mathrm{CPPU}(0.5 \mathrm{mg} / \mathrm{L})$ after 45 days of culture. Statistical analysis revealed that a significant correlation between growth regulators and microshoot induction response at $P<0.05$ level (Figure 1(b); Table 1).

\subsection{Callus Induction Response}

Cotyledon and immature leaf and stem (one explant per tube) segments placed in contact with the solidified MS basal salts with 3.0\% sucrose medium containing various types of hormones resulted different colour and texture of calli. They were allowed to grow up to 60 days. In this case, about $82 \%, 89.7 \%, 75.4 \%$ light green friable of conspicuous callus mass with $795,810,769 \mathrm{mg}$ fresh weight and 220, 265, $210 \mathrm{mg}$ dry weight was obtained per cotyledon, immature leaf and stem explants cultured on medium containing $2.0 \mathrm{mg} / \mathrm{L}$ IBA, respectively. IAA at 2.0 $\mathrm{mg} / \mathrm{L}$ induced $80.9 \%, 85.7 \%$ and $71.7 \%$ light yellow green nodular callusing with an average of 720, 750 and $681 \mathrm{mg}$ fresh mass and 200, 242 and $185 \mathrm{mg}$ dry weight per cotyledon, immature leaf and stem explants after 60 days of culture. Dicamba $(1.0 \mathrm{mg} / \mathrm{L})$ influenced $85.7 \%$ and $94.6 \%$ yellow friable calli with the production of an average of 873 and $900 \mathrm{mg}$ fresh mass and 263 and $293 \mathrm{mg}$ dry weight per cotyledon and immature leaf explants, respectively, whereas the stem explants produced $77.1 \%$ yellow friable calli with an average of $830 \mathrm{mg}$ fresh weight and $222 \mathrm{mg}$ dry weight in the culture. 2,4-D/pCPA/Picloram showed slow response to induce white friable, yellow brown and yellow friable calli for three explants culture. Maximum of $100 \%$ light green nodular callusing efficiency with 975 mg fresh weight and 314 dry weight of callus was observed per immature leaf explants on MS basal medium supplemented with $1.5 \mathrm{mg} / \mathrm{L} \mathrm{NAA}$

Table 1. Effect of phytohormones on multiple shoot induction from shoot-tip explants of safflower cv. NARI-H-15.

\begin{tabular}{|c|c|c|c|c|c|c|c|c|c|c|c|c|c|c|}
\hline & & & & & & & & & \multicolumn{3}{|c|}{ Shoot-tip } & \multicolumn{3}{|c|}{ Node } \\
\hline \multicolumn{9}{|c|}{ MS medium composition (mg/L) } & \multirow{2}{*}{$\begin{array}{c}\text { Mean } \\
\text { no. of } \\
\text { explants }\end{array}$} & \multirow{2}{*}{$\begin{array}{c}\% \text { of } \\
\text { response }\end{array}$} & \multirow{2}{*}{$\begin{array}{c}\text { Mean } \\
\text { no. of shoots }\end{array}$} & \multirow{2}{*}{$\begin{array}{c}\text { Mean } \\
\text { no. of } \\
\text { explants }\end{array}$} & \multirow{2}{*}{$\begin{array}{l}\% \text { of } \\
\text { response }\end{array}$} & \multirow{2}{*}{$\begin{array}{c}\text { Mean } \\
\text { no. of shoots }\end{array}$} \\
\hline BAP & $\mathrm{mT}$ & TDZ & Kin & Zeatin & CPPU & $2-i P$ & Diuron & Monuron & & & & & & \\
\hline 7.0 & - & - & - & - & - & - & - & - & $27.1 \mathrm{~cd}$ & $77.4 \mathrm{~cd}$ & $16.5 \mathrm{e}$ & $25.5 \mathrm{~cd}$ & $72.9 \mathrm{~cd}$ & $14 \mathrm{~d}$ \\
\hline- & 3.5 & 5.0 & - & - & - & - & - & - & $31 b$ & $88.6 b$ & $21 d$ & $28 \mathrm{~b}$ & $80 \mathrm{~b}$ & $19 c$ \\
\hline- & - & - & 1.5 & - & - & - & - & - & $28.2 \mathrm{c}$ & $80.6 c$ & $18 \mathrm{de}$ & $25.8 \mathrm{c}$ & $73.7 \mathrm{c}$ & $17.2 \mathrm{~cd}$ \\
\hline- & - & - & - & - & - & - & - & - & $11 \mathrm{fg}$ & $31.4 \mathrm{~g}$ & 5.4hi & $10.5 \mathrm{fg}$ & $30 \mathrm{fg}$ & $4.4 \mathrm{~g}$ \\
\hline- & - & - & - & 5.0 & - & - & - & - & $14 \mathrm{f}$ & $40 \mathrm{f}$ & $6.0 \mathrm{~h}$ & $12 \mathrm{f}$ & $34.3 \mathrm{f}$ & $5.6 \mathrm{fg}$ \\
\hline- & - & - & - & - & 3.0 & - & - & - & $20.3 \mathrm{~d}$ & $58 \mathrm{~d}$ & $12 \mathrm{f}$ & $19.2 \mathrm{~d}$ & $54.9 \mathrm{~d}$ & 10de \\
\hline- & - & - & - & - & - & 5.0 & - & - & $17 \mathrm{ef}$ & $48.6 \mathrm{ef}$ & $9.3 \mathrm{gh}$ & $16.9 \mathrm{ef}$ & $48.3 \mathrm{ef}$ & $8.1 \mathrm{f}$ \\
\hline- & - & - & - & - & - & - & 3.0 & - & $19.5 \mathrm{de}$ & $55.7 \mathrm{de}$ & $11 \mathrm{fg}$ & $18 \mathrm{de}$ & $51.4 \mathrm{de}$ & $9.5 \mathrm{e}$ \\
\hline \multirow[t]{3}{*}{7.0} & - & - & - & - & 1.5 & - & - & - & $30 \mathrm{bc}$ & $85.7 b c$ & $33.5 c$ & $27.4 \mathrm{bc}$ & $78.3 b c$ & $31 b$ \\
\hline & 3.0 & - & - & - & 0.5 & - & - & - & $34.2 \mathrm{a}$ & $97.7 \mathrm{a}$ & $42.4 \mathrm{a}$ & $33 a$ & $94.3 \mathrm{a}$ & $38 a$ \\
\hline & - & 5.0 & - & - & 0.5 & - & - & - & $31.8 \mathrm{ab}$ & $90.9 \mathrm{ab}$ & $39 \mathrm{ab}$ & $29.5 \mathrm{ab}$ & $84.3 \mathrm{ab}$ & $35 \mathrm{ab}$ \\
\hline
\end{tabular}

Thirty five explants were taken for each experiment. Values are mean of three repeated experiments. Mean within a column followed by the different letters are significantly different according to one way ANOVA and Duncan's multiple range test $(P<0.05)$. 
than cotyledon and stem explants after 60 days of culture. However, CPPU at 1.5 $\mathrm{mg} / \mathrm{L}$ supplemented medium noticed $100 \%$ light green nodular calli in cotyledon (914 fresh weight/290 dry weight) and immature leaf explants (979 fresh weight and 318 dry weight), respectively than stem explants (Figure 1(c); Figure 2(a)(c)).

\subsection{Organogenesis Response}

All type of calli were turned organogenic after 7 - 14 days of culture on plant regeneration medium. The callus tissues cultured on MS basal salts, 3.0\% sucrose and $0.8 \%$ agar medium supplemented with plant growth regulators and their interactions were significant for organogenesis. Among the four cytokinin hormones tested, about $61 \%, 64.3 \%$ and $57.5 \%$ shoot organogenesis with an average of 48.2, 49.5 and 47 number of microshoot buds were observed from cotyledon, immature leaf and stem derived calli, respectively on $7.0 \mathrm{mg} / \mathrm{L}$ BAP tested medium after 45 days of culture. $\mathrm{mT}$ at $4.0 \mathrm{mg} / \mathrm{L}$ induced maximum of $72.5 \%, 82 \%$ and $71 \%$ shoot organogenesis with an average of $58,62.7$ and 55 number of microshoots per cotyledon, immature leaf and stem calli. The explants derived calli cultured on CPPU tested medium showed low response in shoot organogenesis. TDZ at $5.0 \mathrm{mg} / \mathrm{L}$ showed $67.5 \%, 71 \%, 64 \%$ microshoot induction response with an average of 54, 56.5 and 52 number of shoots per cotyledon, immature leaf and stem calli. Further, cotyledon, immature leaf and stem calli cultured on optimum level of TDZ $(5.0 \mathrm{mg} / \mathrm{L})$ and CPPU $(1.5 \mathrm{mg} / \mathrm{L})$ influenced maximum of $95.5 \%, 98 \%$ and $85.8 \%$ shoot induction frequency with an average of $49.7,53.4$ and 45 numbers of microshoots, respectively than that of BAP + Kin or BAP + CPPU or TDZ + Kin tested medium. Optimum level of BAP $(7.0 \mathrm{mg} / \mathrm{L})$ and CPPU $(1.5 \mathrm{mg} / \mathrm{L})$ tested medium noticed $80 \%, 84.8$ and $78 \%$ shoot organogenesis in cotyledon, immature leaf and stem calli. BAP in combinations with Kin or NAA or IAA tested medium showed moderate response in shoot organogenesis of three explants derived calli than BAP + IBA treatment. TDZ $(5.0 \mathrm{mg} / \mathrm{L})$ in combinations with CPPU $(1.5 \mathrm{mg} / \mathrm{L})$ tested medium induced $86.8 \%, 89 \%$ and $83.3 \%$ shoot organogenesis with an average of $63.2,68.5$ and 59 number of microshoots per cotyledon, immature leaf and stem calli than TDZ + NAA or TDZ + Kin treatment. TDZ in combinations with IAA/IBA showed slow response. However, $100 \%$ adventitious shoot organogenesis with an average of 74.7 number of microshoots were noticed to be highest from immature leaf derived calli on $\mathrm{mT}(4.0 \mathrm{mg} / \mathrm{L})+\mathrm{CPPU}(1.5 \mathrm{mg} / \mathrm{L})$ fortified medium than cotyledon and stem calli. $\mathrm{mT}(4.0 \mathrm{mg} / \mathrm{L})+\mathrm{NAA}(1.5 \mathrm{mg} / \mathrm{L})$ or $\mathrm{mT}(4.0 \mathrm{mg} / \mathrm{L})+\mathrm{Kin}(1.5 \mathrm{mg} / \mathrm{L})$ showed moderate response in shoot organogenesis than $\mathrm{mT}+\mathrm{IAA}$ or $\mathrm{mT}+\mathrm{IBA}$ treatment in all culture condition (Figure 1(d), Figure 1(e); Tables 2-4). TDZ and Picloram tested medium did not show useful results in shoot organogenesis through callus culture (data not shown).

\subsection{Rooting and Acclimatization Response}

Root initiation was observed from cutting edge of stem portion of elongated 
Table 2. Effect of phytohormones on multiple shoot induction from cotyledon derived callus explants of safflower cv. NARI-H-15.

\begin{tabular}{|c|c|c|c|c|}
\hline $\begin{array}{c}\text { MS medium } \\
\text { composition }(\mathrm{mg} / \mathrm{L})\end{array}$ & $\begin{array}{c}\text { Mean no. of } \\
\text { callus } \\
\text { explants }\end{array}$ & $\begin{array}{c}\% \text { of } \\
\text { organogenesis }\end{array}$ & $\begin{array}{l}\text { Mean no. of } \\
\text { shoots/callus }\end{array}$ & $\begin{array}{l}\text { Mean shoot } \\
\text { length }(\mathrm{cm})\end{array}$ \\
\hline $7.0 \mathrm{mg} / \mathrm{L}$ BAP & $24.4 \mathrm{hi}$ & $61 \mathrm{hi}$ & $48.2 \mathrm{ij}$ & $0.6 \mathrm{ab}$ \\
\hline $4.0 \mathrm{mg} / \mathrm{L} \mathrm{mT}$ & $29 \mathrm{ef}$ & $72.5 \mathrm{ef}$ & $58 \mathrm{fg}$ & $0.4 \mathrm{~b}$ \\
\hline $5.0 \mathrm{mg} / \mathrm{L} \mathrm{TDZ}$ & $27 \mathrm{~h}$ & $67.5 \mathrm{~h}$ & $54 \mathrm{~h}$ & $0.5 \mathrm{ab}$ \\
\hline $1.5 \mathrm{mg} / \mathrm{L} \mathrm{CPPU}$ & $19.5 \mathrm{k}$ & $48.8 \mathrm{k}$ & $22.7 \mathrm{j}$ & $0.8 \mathrm{a}$ \\
\hline $\begin{array}{c}7.0 \mathrm{mg} / \mathrm{L} \mathrm{BAP}+1.5 \\
\mathrm{mg} / \mathrm{L} \mathrm{Kin}\end{array}$ & $27.7 \mathrm{fg}$ & $69.3 \mathrm{fg}$ & $57.4 \mathrm{~g}$ & $0.5 \mathrm{~b}$ \\
\hline $\begin{array}{c}7.0 \mathrm{mg} / \mathrm{L} \mathrm{BAP}+1.5 \\
\mathrm{mg} / \mathrm{L} \mathrm{CPPU}\end{array}$ & $32 \mathrm{~d}$ & $80 \mathrm{~d}$ & $59 \mathrm{e}$ & $0.4 \mathrm{bc}$ \\
\hline $\begin{array}{c}7.0 \mathrm{mg} / \mathrm{L} \mathrm{BAP}+1.0 \\
\mathrm{mg} / \mathrm{L} \mathrm{NAA}\end{array}$ & $30.8 \mathrm{de}$ & $77 \mathrm{de}$ & $58.5 \mathrm{f}$ & $0.5 \mathrm{~b}$ \\
\hline $\begin{array}{c}7.0 \mathrm{mg} / \mathrm{L} \mathrm{BAP}+1.5 \\
\mathrm{mg} / \mathrm{L} \mathrm{IAA}\end{array}$ & $27.4 \mathrm{~g}$ & $68.5 \mathrm{~g}$ & $54.2 \mathrm{gh}$ & $0.5 \mathrm{~b}$ \\
\hline $\begin{array}{c}7.0 \mathrm{mg} / \mathrm{L} \mathrm{BAP}+1.0 \\
\mathrm{mg} / \mathrm{L} \mathrm{IBA}\end{array}$ & $24 \mathrm{ij}$ & $60 \mathrm{ij}$ & $49.7 \mathrm{i}$ & $0.5 \mathrm{~b}$ \\
\hline $\begin{array}{c}4.0 \mathrm{mg} / \mathrm{L} \mathrm{mT}+1.5 \\
\mathrm{mg} / \mathrm{L} \mathrm{Kin}\end{array}$ & $34.4 \mathrm{bc}$ & $86 \mathrm{bc}$ & $61 \mathrm{bc}$ & $0.4 \mathrm{bc}$ \\
\hline $\begin{array}{c}4.0 \mathrm{mg} / \mathrm{L} \mathrm{mT}+1.5 \\
\mathrm{mg} / \mathrm{L} \mathrm{CPPU}\end{array}$ & $39.7 \mathrm{a}$ & $99.3 \mathrm{a}$ & $68.2 \mathrm{a}$ & $0.3 \mathrm{c}$ \\
\hline $\begin{array}{c}4.0 \mathrm{mg} / \mathrm{L} \mathrm{mT}+1.0 \\
\mathrm{mg} / \mathrm{L} \mathrm{NAA}\end{array}$ & $35.2 \mathrm{ab}$ & $88 \mathrm{ab}$ & $66.6 \mathrm{ab}$ & $0.4 \mathrm{bc}$ \\
\hline $\begin{array}{c}4.0 \mathrm{mg} / \mathrm{L} \mathrm{mT}+1.5 \\
\mathrm{mg} / \mathrm{L} \mathrm{IAA}\end{array}$ & $29.5 \mathrm{e}$ & $73.8 \mathrm{e}$ & $60.4 \mathrm{c}$ & $0.4 \mathrm{bc}$ \\
\hline $\begin{array}{c}4.0 \mathrm{mg} / \mathrm{L} \mathrm{mT}+1.0 \\
\mathrm{mg} / \mathrm{L} \mathrm{IBA}\end{array}$ & $27.2 \mathrm{gh}$ & $68 \mathrm{gh}$ & $59.9 \mathrm{~d}$ & $0.5 \mathrm{~b}$ \\
\hline $\begin{array}{c}5.0 \mathrm{mg} / \mathrm{L} \mathrm{TDZ}+1.5 \\
\mathrm{mg} / \mathrm{L} \text { Kin }\end{array}$ & $32.5 \mathrm{~cd}$ & $81.3 \mathrm{~cd}$ & $58.7 \mathrm{ef}$ & $0.5 \mathrm{~b}$ \\
\hline $\begin{array}{c}5.0 \mathrm{mg} / \mathrm{L} \mathrm{TDZ}+1.5 \\
\mathrm{mg} / \mathrm{L} \mathrm{CPPU}\end{array}$ & $34.7 \mathrm{~b}$ & $86.8 \mathrm{~b}$ & $63.2 \mathrm{~b}$ & $0.4 \mathrm{bc}$ \\
\hline $\begin{array}{c}5.0 \mathrm{mg} / \mathrm{L} \mathrm{TDZ}+1.0 \\
\mathrm{mg} / \mathrm{L} \mathrm{NAA}\end{array}$ & $33.3 \mathrm{c}$ & $83.3 \mathrm{c}$ & $60 \mathrm{~cd}$ & $0.4 \mathrm{bc}$ \\
\hline $\begin{array}{c}5.0 \mathrm{mg} / \mathrm{L} \mathrm{TDZ}+1.5 \\
\mathrm{mg} / \mathrm{L} \mathrm{IAA}\end{array}$ & $27.9 \mathrm{f}$ & $69.8 \mathrm{f}$ & $59.3 \mathrm{de}$ & $0.4 \mathrm{bc}$ \\
\hline $\begin{array}{c}5.0 \mathrm{mg} / \mathrm{L} \mathrm{TDZ}+1.0 \\
\mathrm{mg} / \mathrm{L} \mathrm{IBA}\end{array}$ & $24.1 \mathrm{i}$ & $60.3 \mathrm{i}$ & $52.8 \mathrm{hi}$ & $0.5 \mathrm{~b}$ \\
\hline
\end{tabular}

Forty explants were taken for each experiment. Values are mean of three repeated experiments. Mean within a column followed by the different letters are significantly different according to one way ANOVA and Duncan's multiple range test $(P<0.05)$.

Table 3. Effect of phytohormones on multiple shoot induction from immature leaf derived callus explants of safflower cv. NARI-H-15.

\begin{tabular}{ccccc}
\hline $\begin{array}{c}\text { MS medium } \\
\text { composition } \\
(\mathrm{mg} / \mathrm{L})\end{array}$ & $\begin{array}{c}\text { Mean no. of } \\
\text { callus explants }\end{array}$ & $\begin{array}{c}\text { \% of } \\
\text { organogenesis }\end{array}$ & $\begin{array}{c}\text { Mean no. of } \\
\text { shoots/callus }\end{array}$ & $\begin{array}{c}\text { Mean shoot } \\
\text { length (cm) }\end{array}$ \\
\hline $7.0 \mathrm{mg} / \mathrm{L} \mathrm{BAP}$ & $25.7 \mathrm{i}$ & $64.3 \mathrm{ij}$ & $49.5 \mathrm{i}$ & $0.5 \mathrm{ab}$ \\
$4.0 \mathrm{mg} / \mathrm{L} \mathrm{mT}$ & $32.8 \mathrm{de}$ & $82 \mathrm{de}$ & $62.7 \mathrm{~d}$ & $0.4 \mathrm{~b}$ \\
$5.0 \mathrm{mg} / \mathrm{L} \mathrm{TDZ}$ & $28.4 \mathrm{~g}$ & $71 \mathrm{gh}$ & $56.5 \mathrm{gh}$ & $0.4 \mathrm{~b}$ \\
$1.5 \mathrm{mg} / \mathrm{L} \mathrm{CPPU}$ & $23.7 \mathrm{ij}$ & $59.3 \mathrm{j}$ & $25 \mathrm{ij}$ & $0.6 \mathrm{a}$ \\
$7.0 \mathrm{mg} / \mathrm{L} \mathrm{BAP}+1.5$ & $31.4 \mathrm{ef}$ & $78.5 \mathrm{ef}$ & $58 \mathrm{fg}$ & $0.4 \mathrm{~b}$ \\
\hline
\end{tabular}




\section{Continued}

\begin{tabular}{ccccc}
$7.0 \mathrm{mg} / \mathrm{L} \mathrm{BAP}+1.5 \mathrm{mg} / \mathrm{L} \mathrm{CPPU}$ & $33.9 \mathrm{~cd}$ & $84.8 \mathrm{~cd}$ & $61.3 \mathrm{de}$ & $0.4 \mathrm{~b}$ \\
$7.0 \mathrm{mg} / \mathrm{L} \mathrm{BAP}+1.0 \mathrm{mg} / \mathrm{L} \mathrm{NAA}$ & $31.6 \mathrm{e}$ & $79 \mathrm{e}$ & $59.8 \mathrm{f}$ & $0.5 \mathrm{ab}$ \\
$7.0 \mathrm{mg} / \mathrm{L} \mathrm{BAP}+1.5 \mathrm{mg} / \mathrm{L} \mathrm{IAA}$ & $28 \mathrm{gh}$ & $70 \mathrm{~h}$ & $56 \mathrm{~h}$ & $0.5 \mathrm{ab}$ \\
$7.0 \mathrm{mg} / \mathrm{L} \mathrm{BAP}+1.0 \mathrm{mg} / \mathrm{L}$ IBA & $26.2 \mathrm{hi}$ & $65.5 \mathrm{i}$ & $51.5 \mathrm{hi}$ & $0.5 \mathrm{ab}$ \\
$4.0 \mathrm{mg} / \mathrm{L} \mathrm{mT}+1.5 \mathrm{mg} / \mathrm{L} \mathrm{Kin}$ & $35.3 \mathrm{bc}$ & $88.3 \mathrm{bc}$ & $69.9 \mathrm{~b}$ & $0.4 \mathrm{~b}$ \\
$4.0 \mathrm{mg} / \mathrm{L} \mathrm{mT}+1.5 \mathrm{mg} / \mathrm{L} \mathrm{CPPU}$ & $40 \mathrm{a}$ & $100 \mathrm{a}$ & $74.7 \mathrm{a}$ & $0.3 \mathrm{bc}$ \\
$4.0 \mathrm{mg} / \mathrm{L} \mathrm{mT}+1.0 \mathrm{mg} / \mathrm{L} \mathrm{NAA}$ & $38.4 \mathrm{ab}$ & $96 \mathrm{ab}$ & $71.2 \mathrm{ab}$ & $0.4 \mathrm{~b}$ \\
$4.0 \mathrm{mg} / \mathrm{L} \mathrm{mT}+1.5 \mathrm{mg} / \mathrm{L} \mathrm{IAA}$ & $30.6 \mathrm{ef}$ & $76.5 \mathrm{f}$ & $60.8 \mathrm{e}$ & $0.5 \mathrm{ab}$ \\
$4.0 \mathrm{mg} / \mathrm{L} \mathrm{mT}+1.0 \mathrm{mg} / \mathrm{L} \mathrm{IBA}$ & $29.4 \mathrm{f}$ & $73.5 \mathrm{fg}$ & $58 \mathrm{fg}$ & $0.5 \mathrm{ab}$ \\
$5.0 \mathrm{mg} / \mathrm{L} \mathrm{TDZ}+1.5 \mathrm{mg} / \mathrm{L} \mathrm{Kin}$ & $33 \mathrm{~d}$ & $82.5 \mathrm{~d}$ & $64.2 \mathrm{~cd}$ & $0.4 \mathrm{~b}$ \\
$5.0 \mathrm{mg} / \mathrm{L} \mathrm{TDZ}+1.5 \mathrm{mg} / \mathrm{L} \mathrm{CPPU}$ & $35.6 \mathrm{~b}$ & $89 \mathrm{~b}$ & $68.5 \mathrm{bc}$ & $0.5 \mathrm{ab}$ \\
$5.0 \mathrm{mg} / \mathrm{L} \mathrm{TDZ}+1.0 \mathrm{mg} / \mathrm{L} \mathrm{NAA}$ & $35.2 \mathrm{c}$ & $88 \mathrm{c}$ & $65.9 \mathrm{c}$ & $0.5 \mathrm{ab}$ \\
$5.0 \mathrm{mg} / \mathrm{L} \mathrm{TDZ}+1.5 \mathrm{mg} / \mathrm{L} \mathrm{IAA}$ & $29 \mathrm{fg}$ & $72.5 \mathrm{~g}$ & $60.4 \mathrm{ef}$ & $0.4 \mathrm{~b}$ \\
$5.0 \mathrm{mg} / \mathrm{L} \mathrm{TDZ}+1.0 \mathrm{mg} / \mathrm{L}$ IBA & $26.5 \mathrm{~h}$ & $66.3 \mathrm{hi}$ & $57.3 \mathrm{~g}$ & $0.4 \mathrm{~b}$ \\
\hline
\end{tabular}

Forty explants were taken for each experiment. Values are mean of three repeated experiments. Mean within a column followed by the different letters are significantly different according to one way ANOVA and Duncan's multiple range test $(P<0.05)$.

Table 4. Effect of phytohormones on multiple shoot induction from stem derived callus explants of safflower cv. NARI-H-15.

\begin{tabular}{|c|c|c|c|c|}
\hline $\begin{array}{l}\text { MS medium } \\
\text { composition } \\
(\mathrm{mg} / \mathrm{L})\end{array}$ & $\begin{array}{l}\text { Mean no. of } \\
\text { callus explants }\end{array}$ & $\begin{array}{c}\% \text { of } \\
\text { organogenesis }\end{array}$ & $\begin{array}{l}\text { Mean no. of } \\
\text { shoots/callus }\end{array}$ & $\begin{array}{l}\text { Mean shoot } \\
\text { length }(\mathrm{cm})\end{array}$ \\
\hline $7.0 \mathrm{mg} / \mathrm{L} \mathrm{BAP}$ & $23 \mathrm{i}$ & $57.5 \mathrm{ij}$ & 47.1hi & $0.7 \mathrm{a}$ \\
\hline $4.0 \mathrm{mg} / \mathrm{L} \mathrm{mT}$ & $28.4 \mathrm{e}$ & $71 \mathrm{ef}$ & $55 \mathrm{e}$ & $0.5 \mathrm{ab}$ \\
\hline $5.0 \mathrm{mg} / \mathrm{L} \mathrm{TDZ}$ & $25.6 \mathrm{~g}$ & $64 \mathrm{gh}$ & $52.4 \mathrm{f}$ & $0.5 \mathrm{ab}$ \\
\hline $1.5 \mathrm{mg} / \mathrm{L} \mathrm{CPPU}$ & $17.2 \mathrm{j}$ & $43 j$ & $21 \mathrm{i}$ & $0.5 \mathrm{ab}$ \\
\hline $\begin{array}{c}7.0 \mathrm{mg} / \mathrm{L} \mathrm{BAP}+1.5 \\
\mathrm{mg} / \mathrm{L} \text { Kin }\end{array}$ & $26.2 \mathrm{f}$ & $65.5 \mathrm{fg}$ & $56 \mathrm{de}$ & $0.5 \mathrm{ab}$ \\
\hline $\begin{array}{c}7.0 \mathrm{mg} / \mathrm{L} \mathrm{BAP}+1.5 \\
\mathrm{mg} / \mathrm{L} \mathrm{CPPU}\end{array}$ & $31.2 \mathrm{c}$ & $78 \mathrm{~cd}$ & $57 \mathrm{~cd}$ & $0.4 \mathrm{~b}$ \\
\hline $\begin{array}{c}7.0 \mathrm{mg} / \mathrm{L} \mathrm{BAP}+1.0 \\
\mathrm{mg} / \mathrm{L} \mathrm{NAA}\end{array}$ & $29.8 \mathrm{~d}$ & $74.5 \mathrm{de}$ & $56.8 \mathrm{~d}$ & $0.4 \mathrm{~b}$ \\
\hline $\begin{array}{c}7.0 \mathrm{mg} / \mathrm{L} \mathrm{BAP}+1.5 \\
\mathrm{mg} / \mathrm{L} \mathrm{IAA}\end{array}$ & $26 f g$ & $65 \mathrm{~g}$ & $52 \mathrm{fg}$ & $0.5 \mathrm{ab}$ \\
\hline $\begin{array}{c}7.0 \mathrm{mg} / \mathrm{L} \mathrm{BAP}+1.0 \\
\mathrm{mg} / \mathrm{L} \mathrm{IBA}\end{array}$ & 23.3hi & $58.3 \mathrm{i}$ & $48 \mathrm{~h}$ & $0.5 \mathrm{ab}$ \\
\hline $\begin{array}{c}4.0 \mathrm{mg} / \mathrm{L} \mathrm{mT}+1.5 \\
\mathrm{mg} / \mathrm{L} \mathrm{Kin}\end{array}$ & $32 \mathrm{bc}$ & $80 c$ & $58.5 \mathrm{bc}$ & $0.5 \mathrm{ab}$ \\
\hline $\begin{array}{c}4.0 \mathrm{mg} / \mathrm{L} \mathrm{mT}+1.5 \\
\mathrm{mg} / \mathrm{L} \mathrm{CPPU}\end{array}$ & $37.1 \mathrm{a}$ & $92.8 \mathrm{a}$ & $61.1 \mathrm{a}$ & $0.4 \mathrm{~b}$ \\
\hline $\begin{array}{c}4.0 \mathrm{mg} / \mathrm{L} \mathrm{mT}+1.0 \\
\mathrm{mg} / \mathrm{L} \mathrm{NAA}\end{array}$ & $34 \mathrm{ab}$ & $85 b$ & $59.3 \mathrm{ab}$ & $0.5 \mathrm{ab}$ \\
\hline $\begin{array}{c}4.0 \mathrm{mg} / \mathrm{L} \mathrm{mT}+1.5 \\
\mathrm{mg} / \mathrm{L} \mathrm{IAA}\end{array}$ & $28.5 \mathrm{de}$ & $71.3 \mathrm{e}$ & $55 \mathrm{e}$ & $0.5 \mathrm{ab}$ \\
\hline $\begin{array}{c}4.0 \mathrm{mg} / \mathrm{L} \mathrm{mT}+1.0 \\
\mathrm{mg} / \mathrm{L} \mathrm{IBA}\end{array}$ & $24.9 \mathrm{gh}$ & $62.3 \mathrm{~h}$ & $48.4 \mathrm{gh}$ & $0.5 \mathrm{ab}$ \\
\hline $\begin{array}{c}5.0 \mathrm{mg} / \mathrm{L} \mathrm{TDZ}+1.5 \\
\mathrm{mg} / \mathrm{L} \text { Kin }\end{array}$ & $30.4 \mathrm{~cd}$ & $76 \mathrm{~d}$ & $57.8 \mathrm{c}$ & $0.5 \mathrm{ab}$ \\
\hline
\end{tabular}


Continued

\begin{tabular}{ccccc}
\hline $5.0 \mathrm{mg} / \mathrm{L} \mathrm{TDZ}+1.5 \mathrm{mg} / \mathrm{L} \mathrm{CPPU}$ & $33.3 \mathrm{~b}$ & $83.3 \mathrm{bc}$ & $59 \mathrm{~b}$ & $0.5 \mathrm{ab}$ \\
$5.0 \mathrm{mg} / \mathrm{L} \mathrm{TDZ}+1.0 \mathrm{mg} / \mathrm{L} \mathrm{NAA}$ & $32 \mathrm{bc}$ & $80 \mathrm{c}$ & $57 \mathrm{~cd}$ & $0.5 \mathrm{ab}$ \\
$5.0 \mathrm{mg} / \mathrm{L} \mathrm{TDZ}+1.5 \mathrm{mg} / \mathrm{L} \mathrm{IAA}$ & $26.8 \mathrm{ef}$ & $67 \mathrm{f}$ & $54.2 \mathrm{ef}$ & $0.4 \mathrm{~b}$ \\
$5.0 \mathrm{mg} / \mathrm{L} \mathrm{TDZ}+1.0 \mathrm{mg} / \mathrm{L} \mathrm{IBA}$ & $23.8 \mathrm{~h}$ & $59.5 \mathrm{hi}$ & $50 \mathrm{~g}$ & $0.4 \mathrm{~b}$ \\
\hline
\end{tabular}

Forty explants were taken for each experiment. Values are mean of three repeated experiments. Mean within a column followed by the different letters are significantly different according to one way ANOVA and Duncan's multiple range test $(P<0.05)$.

shoots ( $>0.5$ ) on rooting medium within 7 - 14 days of culture. In this case, individual excised microshoots subcultured on quarter strength MS basal salts, 1.0\% sucrose and $0.8 \%$ agar medium supplemented with optimum level of NAA $(2.0 \mathrm{mg} / \mathrm{L})$ induced $92.8 \%$ (10.5 rootlets/plantlet) and 64\% (5.0 rootlets/plantlet) rooting through micropropagation and organogenesis process, respectively after 30 days of culture. Other auxins such as IAA/IBA showed low rooting response for both in vitro culture methods. High level of NAA and low level of BAP showed $94.8 \%$ (11.5 rootlets/plantlet) and $68 \%$ (5.7 rootlets/plantlet) rooting response through micropropagation and organogenesis methods, respectively. About $95.6 \%$ (12 rootlets/plantlet) and 73.6\% (6.4 rootlets/plantlet) root induction frequency was recorded in plantlets regenerated from micropropagation and organogenesis at NAA $(1.5 \mathrm{mg} / \mathrm{L})$ and CPPU $(0.3 \mathrm{mg} / \mathrm{L})$ treated medium, respectively. However, maximum of $96 \%$ rooting with an average of 12.8 number of rootlets were noticed per plantlet cultured on quarter strength MS basal medium supplemented with NAA $(1.5 \mathrm{mg} / \mathrm{L})$ and $\mathrm{mT}(0.1 \mathrm{mg} / \mathrm{L})$ via micropropagation while about $84 \%$ rooting frequency with an average of 7.3 number of microroots were recorded through organogenesis process after 30 days of culture (Figure 1(f); Table 5). In rooting media, the basal callus formation was higher in IBA or IAA alone tested medium than NAA via organogenesis process while IBA or IAA alone induced low amount of basal callus formation around the stem base of plantlets via micropropagation. The regenerated plants with vigorous healthy roots via micropropagation and organogenesis were acclimatized and showed $67 \%$ and $42 \%$ survival in potting mix after $14-21$ days of transfer (Figure $1(\mathrm{~g})$ ). The in vitro raised plants did not show any morphological abnormalities compared to donor plant during the maturation period after 75 days of transfer to field under green house condition (Figure 1(h)).

\section{Discussion}

\subsection{Shoot Induction and Multiplication via Micropropagation}

The development of plant regeneration systems for safflower has progressed in spite of the high economic value edible crop. The in vitro regeneration response was influenced by the genotypic and seedling age of the explants in incorporated basal salts as well as different plant growth regulators supplemented media at varied concentrations. The use of $\mathrm{mT}$ in tissue culture for enhanced plant regeneration has increased in recent period. The positive effect of exogenous $\mathrm{mT}$ on plant regeneration has been reported in other plant species [25] [26]. The 
Table 5. Effect of phytohormones on root induction in safflower (Carthamus tinctorius L.) cv. NARI-H-15.

\begin{tabular}{|c|c|c|c|c|c|c|c|c|}
\hline \multirow[b]{2}{*}{$\begin{array}{l}\text { 1/4 MS medium } \\
\text { composition } \\
(\mathrm{mg} / \mathrm{L})\end{array}$} & \multicolumn{4}{|c|}{ Micropropagation } & \multicolumn{4}{|c|}{ Organogenesis } \\
\hline & $\begin{array}{c}\text { Mean } \\
\text { no. of } \\
\text { plantlets }\end{array}$ & $\begin{array}{l}\% \text { of } \\
\text { rooting }\end{array}$ & $\begin{array}{c}\text { Mean no. } \\
\text { of } \\
\text { roots/plantlets }\end{array}$ & $\begin{array}{l}\text { Basal callus } \\
\text { formation }\end{array}$ & $\begin{array}{l}\text { Mean no. } \\
\text { of plantlets }\end{array}$ & $\begin{array}{c}\% \text { of } \\
\text { rooting }\end{array}$ & $\begin{array}{c}\text { Mean no. } \\
\text { of } \\
\text { roots/plantlets }\end{array}$ & $\begin{array}{l}\text { Basal callus } \\
\text { formation }\end{array}$ \\
\hline $\begin{array}{c}\text { NAA } \\
2.0\end{array}$ & $23.2 \mathrm{c}$ & $92.8 \mathrm{c}$ & $10.5 \mathrm{c}$ & $\begin{array}{c}\text { + Low basal } \\
\text { callus }\end{array}$ & $16 \mathrm{~cd}$ & $64 d$ & $5.0 \mathrm{c}$ & $\begin{array}{c}\text { + Low basal } \\
\text { callus }\end{array}$ \\
\hline $\begin{array}{c}\text { IAA } \\
1.5\end{array}$ & $18 \mathrm{~d}$ & $72 \mathrm{~d}$ & $2.5 \mathrm{~d}$ & $\begin{array}{c}\text { + Low basal } \\
\text { callus }\end{array}$ & $13 \mathrm{e}$ & $52 \mathrm{e}$ & $1.7 \mathrm{~d}$ & $\begin{array}{c}++ \text { More } \\
\text { basal callus }\end{array}$ \\
\hline $\begin{array}{c}\text { IBA } \\
1.5\end{array}$ & $9.4 \mathrm{e}$ & $37.6 \mathrm{e}$ & $1.1 \mathrm{e}$ & $\begin{array}{c}+ \text { Low basal } \\
\text { callus }\end{array}$ & $8.1 \mathrm{f}$ & $32.4 \mathrm{f}$ & $0.8 \mathrm{e}$ & $\begin{array}{c}++ \text { More } \\
\text { basal callus }\end{array}$ \\
\hline $\begin{array}{c}\mathrm{NAA}+\mathrm{BAP} \\
2.0+0.1\end{array}$ & $23.7 \mathrm{~b}$ & $94.8 \mathrm{~b}$ & $11.5 \mathrm{~b}$ & - & $17 \mathrm{bc}$ & $68 \mathrm{c}$ & $5.7 \mathrm{~b}$ & - \\
\hline $\begin{array}{c}\mathrm{NAA}+\mathrm{CPPU} \\
1.5+0.3\end{array}$ & $23.9 \mathrm{ab}$ & $95.6 \mathrm{ab}$ & $12.0 \mathrm{ab}$ & - & $18.4 \mathrm{~b}$ & $73.6 \mathrm{~b}$ & $6.4 \mathrm{ab}$ & - \\
\hline $\begin{array}{c}\mathrm{NAA}+\mathrm{mT} \\
1.5+0.1\end{array}$ & $24 \mathrm{a}$ & $96 a$ & $12.8 \mathrm{a}$ & - & $21 \mathrm{a}$ & $84 a$ & $7.3 \mathrm{a}$ & - \\
\hline $\begin{array}{c}\mathrm{NAA}+\mathrm{AgNO}_{3} \\
1.5+0.5\end{array}$ & $23.6 \mathrm{bc}$ & $94.4 \mathrm{bc}$ & $11.1 \mathrm{bc}$ & - & $16.7 \mathrm{c}$ & $66.8 \mathrm{~cd}$ & $5.2 \mathrm{bc}$ & - \\
\hline
\end{tabular}

+ Low basal callus, ++ More basal callus, - No basal callus; Twenty five explants were taken for each experiment. Values are mean of three repeated experiments. Mean within a column followed by the different letters are significantly different according to one way ANOVA and Duncan's multiple range test $(P$ $<0.05)$.

information regarding utilization of $\mathrm{mT}$ on plant regeneration is less focused till now. Hence, in the present study, an attempt was made to investigate the synergetic effect of BAP or $\mathrm{mT}$ or TDZ and CPPU of various levels on plant regeneration from 7 - 9 day old shoot-tip and node explants of safflower cv. NARI-H-15 via micropropagation. The effect of BAP or TDZ has no major impact on rate of plant regeneration than $\mathrm{mT}$ in the media. In earlier, Amoo et al. [27] reported that the treatment of $\mathrm{mT}$ has shown a promise role to influence high frequency plant regeneration when compared to TDZ in micropropagation of Merwilla plumbea. However, in our study, mT had highly significant effects $(P<0.05)$ in addition with CPPU on plant regeneration from shoot-tip explants. Similarly, the aromatic cytokinin $\mathrm{mT}$ promotes in vitro propagation, shoot quality and micrografting was produced in Corylus colurna [28]. These finding are in contrast with Basalma et al. [14] reports that have proved that the highest percentage of shoot regeneration per explants of safflower cv. Dinçer achieved on a MS medium containing TDZ and IBA. Our present finding is also not supported with other reports demonstrating that the urea-type cytokinins, TDZ and CPPU was more effective for the induction and the morphogenesis of adventitious multiple shoots from cotyledonary node explants of M. crystallinum plants than BAP [29].

\subsection{Callus Induction and Proliferation}

In addition, callus induction from cotyledon, immature leaf and stem explants of safflower cv. NARI-H-15 was investigated on MS medium supplemented with various levels of an individual hormones, NAA, IBA, IAA, 2,4-D, Dicamba, $\mathrm{CPPU}, \mathrm{pCPA}$ and picloram at 0.5 to $2.5 \mathrm{mg} / \mathrm{L}$. There were significant differences in the callus induction from the variations of the explants and various types of 

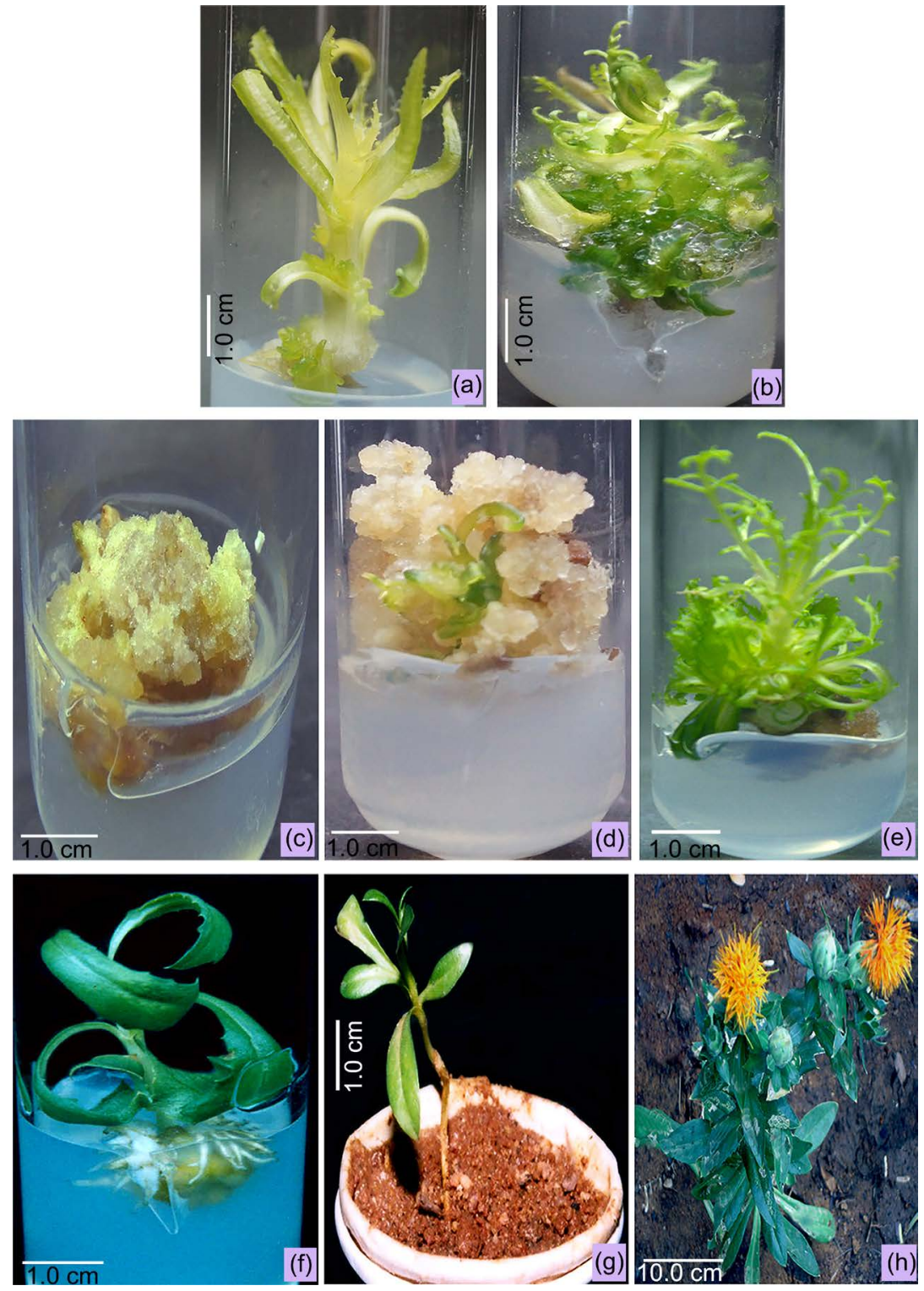

Figure 1. Effect of $\mathrm{mT}$ and CPPU on plant regeneration from shoot-tip meristem and immature leaf calli of safflower cv. NARI-H-15. $(a, b)$ Initiation and proliferation of microshoots from a cultured shoot-tip explants on MS basal medium supplemented with $\mathrm{mT}(3.0 \mathrm{mg} / \mathrm{L})+\mathrm{CPPU}(0.5 \mathrm{mg} / \mathrm{L})$ after 45 days in culture. (c) Induction of light green nodular calli from immature leaf explants on $1.5 \mathrm{mg} / \mathrm{L}$ CPPU fortified medium after 60 days in culture. $(\mathrm{d}, \mathrm{e})$ Initiation and proliferation of microshoots from organogenic calli on $\mathrm{mT}(4.0 \mathrm{mg} / \mathrm{L})+$ CPPU $(1.5 \mathrm{mg} / \mathrm{L})$ fortified medium after 45 days in culture. (f) In vitro shoots rooted on 1/2 MS supplemented with NAA $(1.5 \mathrm{mg} / \mathrm{L})$ and $\mathrm{mT}(0.1 \mathrm{mg} / \mathrm{L})$ after 30 days of culture. (g) An acclimatized plant in paper cup containing red soil, garden soil and sand (1:2:1) mixture after 14 - 20 days of transfer. (f) Field survived mature plants under green house condition after 75 days of transfer to field under green house condition.

growth regulators tested media after 14 - 20 days of culture initiation (Figure 1(a)). Most of explants cultured on CPPU or NAA formed callus in all concentrations than other auxins tested. Earlier, Chavhan et al. [17] reported that the level of NAA and BAP was found best for callus induction from cotyledonary 


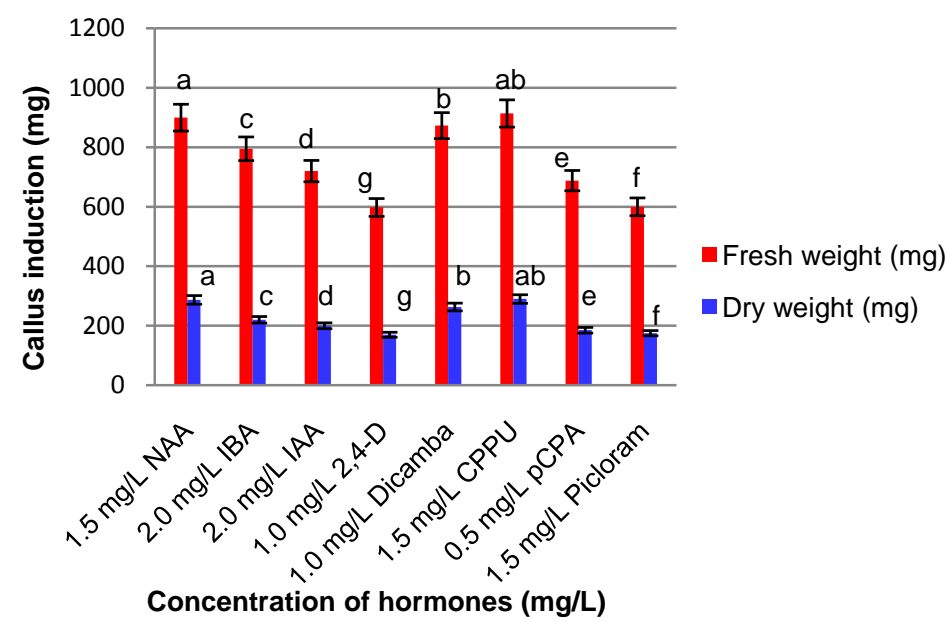

(a)

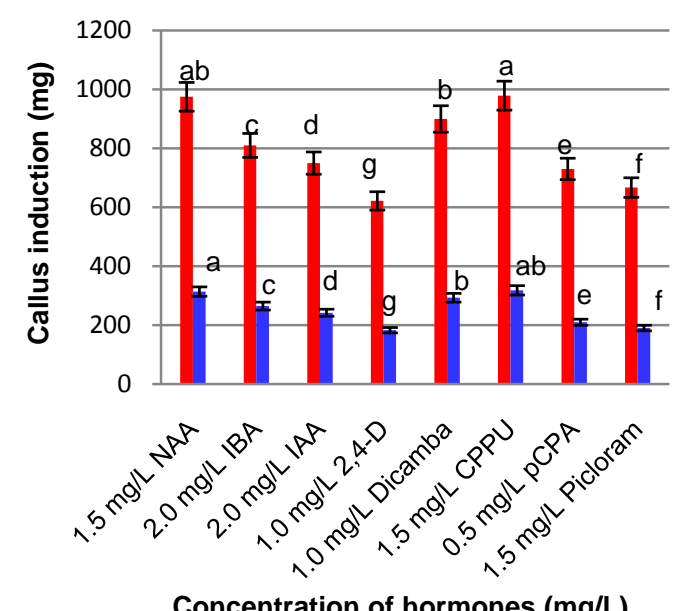

- Fresh weight $(\mathrm{mg})$

- Dry weight $(\mathrm{mg})$

(b)

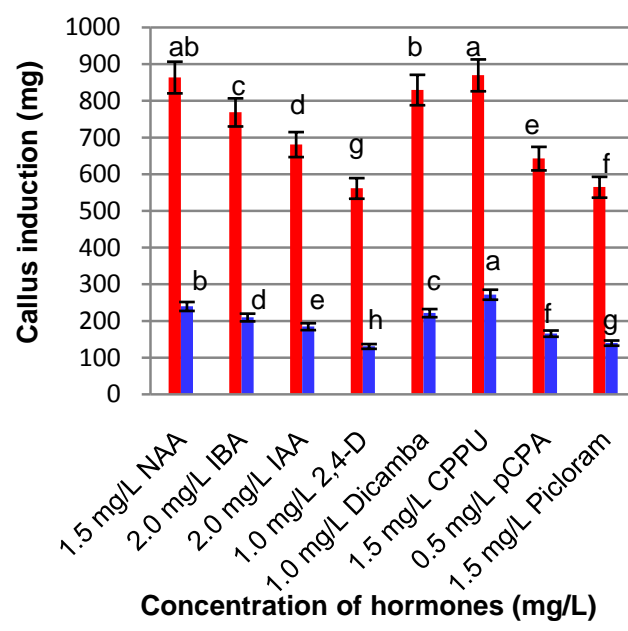

- Fresh weight (mg)

- Dry weight (mg)

(c)

Figure 2. (a). Effect of phytohormones on callus induction from cotyledon explants of safflower cv. NARI-H-15. (b) Effect of phytohormones on callus induction from immature leaf explants of safflower (C. tinctorius L.) cv. NARI-H-15. (c) Effect of phytohormones on callus induction from stem explants of safflower cv. NARI-H-15. Mean within a column followed by the different letters are significantly different according to one way ANOVA and Duncan's multiple range test $(P<0.05)$. 
leaf disc explants of safflower cv Shardha and PBN 12 in comparison with other levels of NAA. Ghasempour et al. [18] study showed that the best result of significant callus induction was obtained from leaf of safflower cv. Lesaf on BAP tested medium after 25 - 30 days whereas hypocotyls produced moderate amount of callus on 2,4-D, NAA and BAP tested medium. But our earlier study showed that cotyledon explants of safflower cv. NARI-6 on MSG basal salts, myo-inositol, T. $\mathrm{HCl}$ medium supplemented with picloram produced more amount of callus [15]. However, in the present study we observed that CPPU was found superior to reveal significant result in callusing from cotyledon and immature leaf explants than NAA. Dicamba or IBA tested medium showed moderate response in callusing in all three explants than IAA, pCPA, 2,4-D and Picloram treated medium.

\subsection{Shoot Organogenesis Response}

Further, the callus morphology and adventitious shoot development was varied depend upon types, combination and concentrations of growth hormones in plant regeneration medium. In the present study, callus derived from cotyledons, immature leaf and stem of safflower cv. NARI-H-15 cultured on MS medium supplemented with various concentrations of individual hormones, BAP or $\mathrm{mT}$ or $\mathrm{TDZ}$ or $\mathrm{CPPU}$ alone or $\mathrm{BAP}$ or $\mathrm{mT}$ or $\mathrm{TDZ}$ in combinations with Kin or CPPU or NAA or IAA or IBA on shoot organogenesis was investigated. Among them BAP in combinations with CPPU showed satisfactory results in production of shoots from immature leaf calli than cotyledon and stem calli while BAP and NAA showed slow response in shoot organogenesis. In contrast, shoot regeneration was best from different explants derived calli of safflower $\mathrm{cv}$ Shardha, PBN 12 [17], Lesaf [18] and wild safflower (C. persicus Wild) [30] on MS supplemented with high level of BAP with low level of NAA. Earlier, we reported that embryogenic callus subcultured on MSG basal medium with TDZ and Picloram was developed more numbers of shoots from organogenic calli [15]. Basalma et al. [14] also reported the efficacy of various concentrations of TDZ and IBA on adventitious shoot regeneration from calli of cotyledonary leaves of safflower cv. Dinçer. Nikhil et al. [31] study also showed that best shoot induction response was obtained in different explants of safflower cv. AKS-207 in TDZ and NAA selective medium while leaf segments of Carthamus arborescens showed high frequency of shoot regeneration on TDZ and NAA treatment [13]. The contrast could be due to differences in cultivars, physiological state and age of explants. However, in the present observation, calli derived from immature leaf produced highest number of shoots than other explants in TDZ and CPPU tested medium. CPPU has been shown to possess a stronger cytokinin like activity to TDZ than combined action of other hormones for induction of high frequency of healthy adventitious shoot organogenesis from immature leaf derived calli. In other hand, the use of $\mathrm{mT}$ could be a new source of cytokinins with high morphogenetic activity. Proportion-dependent effects were recorded for larger numbers of shoots regeneration from different explants derived calli 
on $\mathrm{mT}$ alone or in combinations with Kin or NAA or IAA or IBA. However, the shoot induction frequency was significantly $(P<0.05)$ increased and found to be greatest without formation of hyperhydricity in immature leaf calli than cotyledon and stem derived calli of safflower cv. NARI-H-15 on mT and CPPU treated medium. Similar results were reported with the $\mathrm{mT}$ treatments of potato [32] and Aloe polyphylla [22]. The use of $\mathrm{mT}$ and its derivatives has been recommended as a potential replacement for BAP [26], TDZ and other cytokinins in plant tissue culture industry. This is evident that callusing and shoot regeneration responses in safflower are purely genotype as well as species specific.

\subsection{Rooting and Acclimatization Response}

Moreover, the influence of culture conditions in rooting of safflower cv. NARI-H-15 plantlets was investigated further by transferring of plantlets from initial culture conditions to newly prepared medium with different plant growth regulators. The regenerated shoots were rooted after 30 days of culture in all treatment. There was no significant difference between MS media supplemented with NAA alone or NAA + BAP or NAA $+\mathrm{AgNO}_{3}$ in terms of rooting per plantlets. The plantlets cultured on NAA + CPPU tested medium showed moderate response in terms of high frequency rooting of plantlets regenerated via micropropagation and organogenesis process (Figure 1(a)). Our earlier reports showed that the better rooting response was observed in plantlets of safflower cv. NARI-6 on NAA [11] or NAA and $\mathrm{AgNO}_{3}$ tested media [15]. In contrast, the necessity of using IBA for roots induction of tissue culture plants of wild safflower was reported by Özdemir and Türker [30]. Chavhan et al. [17] study indicated that the rooting response of the regenerated $\mathrm{cv}$. Sharda and PBN-12 plantlets was very poor on MS supplemented with $7.0 \%$ sucrose while inefficient rooting result was recorded on MS medium containing 7\% - 8\% sucrose and IAA [9]. However, it was evident that NAA in addition with $\mathrm{mT}$ exhibited significant $(P<0.05)$ results of better rooting without callus interception from regenerated plantlets of safflower cv. NARI-H-15 via micropropagation than organogenesis. In a similar fashion, low concentration of $\mathrm{mT}$ was resulted more roots in Musca [33] and turmeric [21] plants. The average root length within short time and reduce the expenditure coupled with tissue culture may have an optimistic influence on the survival of the plants. However, the acclimatized plants showed maximum survival rate in pots containing of soil mixture under green house condition. The transplanted in vitro plants in the field exhibited better survival and grown to mature plants.

\section{Conclusion}

The establishment of a successful efficient regeneration system suggests that meta-topolin in addition with CPPU may act as a new source of potential cytokinins and it is highly recommended for in vitro regeneration of safflower $\mathrm{cv}$. NARI-H-15 for large scale production. It could be highly applicable to maintain the genetic stability of many cultivars of this genotype and would certainly help 
in increasing safflower cultivation area in the world. In addition, the optimized regeneration protocol might be efficiently preferred to overcome the demand of raw material of safflower for plant based drug production, regeneration of new genotypes with improved productivity, resistance to biotic and abiotic factors through in vitro selection process and Agrobacterium mediated genetic transformation to modify genetic characteristics of agronomic traits in improvement of fatty acid contents in seed oil with enhancing the level of $\alpha$ tocopherol production in many cultivars of single genotypic safflower plant.

\section{Acknowledgements}

The authors are grateful to The Principal, Dr. V. Pandiyarajan, Ayya Nadar Janaki Ammal College, Sivakasi, TN for providing all laboratory facilities and encouragement. Our sincere thanks to NARI, Maharashtra, India for supplying of safflower cv. NARI-H-15 seeds for the present study. Department of Science \& Technology (DST), New Delhi, India is duly acknowledged for sponsoring SERB-YS project with financial support to carry out the present research work.

\section{References}

[1] Weiss, E.A. (2000) Oilseed Crops. 2nd Edition, Blackwell Science, Malden, 259-273.

[2] Nimbkar, N. (2002) Safflower Rediscovered. Times Agricultural Journal, 2, 32-36.

[3] George, L. and Rao, P.S. (1982) In Vitro Manipulation of Safflower (Carthamus tinctorius L.) through Tissue Culture. Proceedings of the National Academy of Sciences, India Section B: Biological Sciences, 48, 791-794.

[4] Tejovathi, G. and Anwar, S.Y. (1987) Plant Regeneration from Cotyledonary Cultures of Safflower (Carthamus tinctorius L.). In: Reddy, G.M., Ed., Plant Cell and Tissue Culture of Economically Important Plants, Osmania University, Hyderabad, 347-353.

[5] Tejovathi, G. and Anwar, S.Y. (1993) 2,4,5-Trichloro Phenoxy Propionic Acid Induced Rhizogenesis in Carthamus tinctorius L. Proceedings of the Indian National Science Academy, Part B, Biological Sciences, 59, 633-636.

[6] Orlikowska, T.K. and Dyer, W.E. (1993) In Vitro Regeneration and Multiplication of Safflower (Carthamus tinctorius L.). Plant Science, 93, 151-157. https://doi.org/10.1016/0168-9452(93)90044-Z

[7] Sujatha, M. and Suganya, A. (1996) In Vitro Organogenic Comparison of Different Seedling Tissues of Safflower (Carthamus tinctorius L.). Sesame Safflower News Letter, 11, 85-90.

[8] Ying, M., Dyer, W.E. and Bergman, J.W. (1992) Agrobacterium tumefaciensMediated Transformation of Safflower (Carthamus tinctorius L.) cv. Centennial. Plant Cell Reports, 11, 581-585. https://doi.org/10.1007/BF00233097

[9] Nikam, T.D. and Shitole, M.G. (1999) In Vitro Culture of Safflower (Carthamus tinctorius L.) cv. Bhima: Initiation, Growth Optimization and Organogenesis. Plant Cell Tissue and Organ Culture, 55, 15-22. https://doi.org/10.1023/A:1026493616991

[10] Walia, N., Kaur, A. and Babbar, S.B. (2005) In Vitro Regeneration of a High OilYielding Variety of Safflower (Carthamus tinctorius var HUS-305). Journal of Plant Biochemistry and Biotechnology, 14, 65-68. https://doi.org/10.1007/BF03263229

[11] Vijayakumar, J. and Ranjitha Kumari, B.D. (2005) Effect of Phytohormones on Multiple Shoot Induction in cv. NARI-6 of Safflower (Carthamus tinctorius L.). 
Journal of Plant Biotechnology, 7, 149-153.

[12] Radhika, K., Sujatha, M. and Nageshwar Rao, T. (2006) Thidiazuron Stimulates Adventitious Shoot Regeneration in Different Safflower Explants. Biologia Plantarum, 50, 174-179. https://doi.org/10.1007/s10535-006-0003-7

[13] Sujatha, M. and Dinesh, K.V. (2007) In Vitro Bud Regeneration of Carthamus tinctorius and Wild Carthamus Species from Leaf Explants and Axillary Buds. Biologia Plantarum, 51, 782-786. https://doi.org/10.1007/s10535-007-0160-3

[14] Basalma, D., Uranbey, S., Mirici, S. and Kolsarici, O. (2008) TDZ x IBA Induced Shoot Regeneration from Cotyledonary Leaves and in Vitro Multiplication in Safflower (Carthamus tinctorius L.). African Journal of Biotechnol. 7, 960-966.

[15] Vijayakumar, J., Ranjitha Kumari, B.D. and Castano, E. (2008) Cyclic Somatic Embryogenesis and Efficient Plant Regeneration from Callus of Safflower. Biologia Plantarum, 52, 429-436. https://doi.org/10.1007/s10535-008-0087-3

[16] Vijayakumar, J., Ranjitha Kumari, B.D., Sujatha, G. and Castano, E. (2008) Production of Plants Resistant to Alternaria carthami via Organogenesis and Somatic Embryogenesis of Safflower cv. NARI-6 Treated With Fungal Culture Filtrates. Plant Cell Tissue Organ Culture, 93, 85-96. https://doi.org/10.1007/s11240-008-9346-4

[17] Chavhan, R.L., Patade, V.Y. and Patil, H.B. (2008) In Vitro Studies on Callus Induction and Plantlet Regeneration in Safflower (Carthamus tinctorius L.). Asian Journal of Bio Science, 3, 231-232.

[18] Ghasempour, H., Soheilikhah, Z., Zebarjadi, A.R., Ghasempour, S. and Karimi, N. (2014) In Vitro Micropropagation, Callus Induction and Shoot Regeneration in Safflower L. cv. Lesaf. Iranian Journal of Plant Physiology, 4, 999-1004.

[19] Strnad, M., Hanus, J., Vanek, T., Kaminek, M., Ballantine, J., Fussell, B. and Hanke, D. (1997) Meta-Topolin, a Highly Active Aromatic Cytokinin from Poplar Leaves (Populus canadensis Moench, cv. Robusta). Phytochemistry, 45, 213-218. https://doi.org/10.1016/S0031-9422(96)00816-3

[20] Kubalakova, M. and Strnad, M. (1992) The Effect of Aromatic Cytokinins (Populins) on Micropropagation and Regeneration in Vitro. Biologia Plantarum, 34, 578579.

[21] Salvi, N., George, L. and Eapen, S. (2002) Micropropagation and Field Evaluation of Micropropagated Plants of Turmeric. Plant Cell Tissue and Organ Culture, 68, 143 151. https://doi.org/10.1023/A:1013889119887

[22] Bairu, M., Stirk, W., Dolezal, K. and Van Staden, J. (2007) Optimizing the Micropropagation Protocol for the Endangered Aloe polyphylla: Can Meta-Topolin and Its Derivatives Serve as Replacement for Benzyladenine and Zeatin? Plant Cell Tissue and Organ Culture, 90, 15-23. https://doi.org/10.1007/s11240-007-9233-4

[23] Bairu, M., Stirk, W., Dolezal, K. and Van Staden, J. (2008) The Role of Topolins in Micropropagation and Somaclonal Variation of Banana Cultivars "Williams" and "Grand Naine" (Musa spp. AAA). Plant Cell Tissue and Organ Culture, 95, 373 379. https://doi.org/10.1007/s11240-008-9451-4

[24] Murashige, T. and Skoog, F. (1962) A Revised Medium for Rapid Growth and Bioassay With Tobacco Tissue Culture. Physiologia Plantarum, 15, 473-497. https://doi.org/10.1111/j.1399-3054.1962.tb08052.x

[25] Podwyszyńska, M., Węgrzynowicz-Lesiak, E., Dolezal, K., Krekule, K., Strnad, M. and Saniewski, M. (2012) New Cytokinin-Meta-Methoxytopolins in Micropropagation of Cotinus coggygria Scop. "Royal Purple". Propagation of Ornamental Plants, 12, 220-228.

[26] Dimitrova, N., Nacheva, L. and Berova, M. (2016) Effect of Meta-Topolin on the Shoot Multiplication of Pear Rootstock OHF-333 (Pyrus communis L.). Hortorum 
Cultus-Acta Scientiarum Polonorum, 15, 43-53.

[27] Amoo, S.O., Aremu, A.O., Moyo, M., Sunmonu, T.O., Plíhalová, L., Doležal, K. and Staden, J.V. (2015) Physiological and Biochemical Effects of a TetrahydropyranylSubstituted Meta-Topolin in Micropropagated Merwilla plumbea. Plant Cell Tissue and Organ Culture, 121, 579-590. https://doi.org/10.1007/s11240-015-0728-0

[28] Gentile, A., Frattarelli, A., Nota, P., Condello, E. and Caboni, E. (2016) The Aromatic Cytokinin Meta-Topolin Promotes in Vitro Propagation, Shoot Quality and Micrografting in Corylus colurna L. Plant Cell Tissue and Organ Culture, 128, 693-703. https://doi.org/10.1007/s11240-016-1150-y

[29] Sunagawa, H., Agarie, S., Umemoto, M., Makishi, Y. and Nose, A. (2007) Effect of Urea-Type Cytokinins on the Adventitious Shoots Regeneration From Cotyledonary Node Explant in the Common Ice Plant, Mesembryanthemum crystallinum. Plant Production Science, 10, 47-56. https://doi.org/10.1626/pps.10.47

[30] Özdemir, F.A. and Türker, M. (2014) Effect of Different Combinations of BAP and NAA in Vitro Propagation of Wild Safflower (Carthamus persicus Wild). Yuzuncu Yil University Journal of Agricultural Sciences, 24, 30-35.

[31] Nikhil, M., Dudhare, M.S., Jadhav, P.V., Moharil, M.P. and Deshmukh, A.G. (2014) In Vitro Shoot Regeneration and Plantlet Development in Safflower (Carthamus tinctorius L.). The Bioscan, 9, 551-555.

[32] Baroja-Fernandez, E., Aguirreolea, J., Martienkova, H., Hanus, J. and Strnad, M. (2002) Aromatic Cytokinins in Micropropagated Potato Plants. Plant Physiology and Biochemistry, 40, 217-224. https://doi.org/10.1016/S0981-9428(02)01362-1

[33] Escalona, M., Cejas, I., Gonzalez-Olmedo, J., Capote, I., Roels, S., Canal, M.J., Rodriguez, R. and Debergh, P. (2003) The Effect of Meta-Topolin on Plantain Propagation Using a Temporary Immersion Bioreactor. InfoMusa, 12, 28-30.

\section{Submit or recommend next manuscript to SCIRP and we will provide best service for you:}

Accepting pre-submission inquiries through Email, Facebook, LinkedIn, Twitter, etc. A wide selection of journals (inclusive of 9 subjects, more than 200 journals) Providing 24-hour high-quality service

User-friendly online submission system

Fair and swift peer-review system

Efficient typesetting and proofreading procedure

Display of the result of downloads and visits, as well as the number of cited articles Maximum dissemination of your research work

Submit your manuscript at: http://papersubmission.scirp.org/

Or contact ajps@scirp.org 